\title{
Discovery of microarray-identified genes associated with ovarian cancer progression
}

\author{
XIA LIU $^{1 *}$, YUTAO GAO $^{2 *}$, BINGBING ZHAO $^{3}$, XIAOFENG LI $^{4}, \mathrm{YI} \mathrm{LU}^{1}$, \\ JIAN ZHANG ${ }^{1}$, DANRONG LI ${ }^{5}, \mathrm{LI} \mathrm{LI}^{3,5}$ and FUQIANG YIN ${ }^{5,6}$ \\ ${ }^{1}$ Center for Translational Medicine, Guangxi Medical University, Nanning, Guangxi 530021; ${ }^{2}$ Department of Obstetrics \\ and Gynecology, Beijing Chao-Yang Hospital, Affiliated to Capital Medical University, Beijing 100020; \\ ${ }^{3}$ Department of Gynecologic Oncology, Affiliated Tumor Hospital of Guangxi Medical University, Nanning, \\ Guangxi 530021; ${ }^{4}$ The Orthopedics and Traumatology Hospital of Guangxi, Nanning, Guangxi 530022; \\ ${ }^{5}$ Medical Scientific Research Centre, Guangxi Medical University, Nanning; ${ }^{6}$ Key Laboratory of High-Incidence- \\ Tumor Prevention and Treatment (Guangxi Medical University), Ministry of Education, Nanning, Guangxi 530021, P.R. China
}

Received February 26, 2015; Accepted April 9, 2015

DOI: 10.3892/ijo.2015.2971

\begin{abstract}
Ovarian cancer is the most lethal cancer of female reproductive system. There is a consistent and urgent need to better understand its mechanism. In this study, we retrieved 186 genes that were dysregulated by at least 4-fold in 594 ovarian serous cystadenocarcinomas in comparison with eight normal ovaries, according to The Cancer Genome Atlas Ovarian Statistics data deposited in Oncomine database. DAVID analysis of these genes enriched two biological processes indicating that the cell cycle and microtubules might play critical roles in ovarian cancer progression. Among these 186 genes, 46 were dysregulated by at least 10 -fold and their expression was further confirmed by the Bonome Ovarian Statistics data deposited in Oncomine, which covered 185 cases of ovarian carcinomas and 10 cases of normal ovarian surface epithelium. Six genes, including aldehyde dehydrogenase 1 family, member A2 (ALDH1A2), alcohol dehydrogenase 1B (class I), $\beta$ polypeptide $(A D H 1 B)$, NEL-like 2 (chicken) (NELL2), hemoglobin, $\beta$ (HBB), ATP-binding cassette, subfamily A (ABC1), member 8 (ABCA8) and hemoglobin, $\alpha 1$ (HBA1) were identified to be downregulated by at least 10 -fold in 779 ovarian cancers compared with 18 normal controls. Using mRNA expression profiles retrieved from microarrays deposited in the Gene Expression Omnibus Profiles database, RT-qPCR measurement and bioinformatics analysis, we further indicated that high expression of $H B B$ might predict a poorer
\end{abstract}

Correspondence to: Dr Fuqiang Yin, Medical Scientific Research Centre, Guangxi Medical University, 22 Shuangyong Road, Nanning, Guangxi 530021, P.R. China

E-mail: yinfq@mail2.sysu.edu.cn

*Contributed equally

Key words: ovarian cancer, microarray, progression, bioinformatics 5-year survival, high expression of $A L D H 1 A 2$ and $A B C A 8$ might predict a poor outcome; while $A L D H 1 A 2, A D H 1 B$, $H B B$ and $A B C A 8$, in particular the former two genes, might be associated with drug resistance, and ALDH1A2 and NELL2 might contribute to invasiveness and metastasis in ovarian cancer. This study thus contributes to our understanding of the mechanism of ovarian cancer progression and development, and the six identified genes may be potential therapeutic targets and biomarkers for diagnosis and prognosis.

\section{Introduction}

Ovarian cancer is one of the five leading causes of cancer death in women (1). Analysis of overall five-year survival rates for women with ovarian cancer indicates some improvement in the last 30 years (1975-2009) (2). Nonetheless, these gains are rather modest and there clearly remains a need to better understand the molecular mechanism of ovarian cancer progression to identify new drug targets and biomarkers.

Computational approach-based bioinformatics analyses that utilize diverse biological datasets to generate automated predictions are useful, as they can guide laboratory experiments and facilitate more rapid annotation of genomes (3). Bioinformatics analyses have relied on a variety of genomic and proteomic data, not least including usage of microarray expression data (4), protein/gene interaction networks (5), and the annotation of genes with biological processes (6). Thus, based on many large-scale databases and networks, bioinformatics analysis is a potential, feasible and valuable way to mine data and predict gene function (3). For instance, by retrieving data from The Cancer Genome Atlas (TCGA) Ovarian Statistics dataset, Hsu et al (7) successfully identified a group of genes associated with chemotherapy response in ovarian cancer. Similarly, by comprehensive bioinformatics analysis including mRNA expression data retrieval, protein/gene interaction and biological processes analysis, we revealed that upregulation of NIMA-related kinase 2 (NEK2) (8), and downregulation of NIMA-related kinase 11 (NEK11) (9), ribonuclease T2 
(RNASET2), gametogenetin binding protein 2 (GGNBP2) (10) and SPARC-like 1 (hevin) (SPARCL1) (11) all contribute to the regulation of drug resistance in ovarian cancer.

In this study, using mRNA expression profiles retrieved from the Oncomine online database, we annotated several biological processes that are closely associated with ovarian cancer progression and development. In total, we identified six genes that were downregulated by at least 10 -fold in ovarian cancer. Using mRNA expression data retrieved from the Gene Expression Omnibus (GEO) Profiles database and RT-qPCR measurement, we further interrogated the phenotypic characteristics of the six genes in ovarian cancer by comprehensive bioinformatics analyses.

\section{Materials and methods}

Cell culture. The human epithelial ovarian cancer A2780 and SKOV3 cells were maintained in our laboratory. Cisplatinresistant cell line A2780-DDP and SKOV3-DDP, and carboplatin-resistant cell line A2780-CBP were established by sequential exposure of cells to increasing concentrations of carboplatin and cisplatin, respectively. The resistance index of A2780-DDP, -CBP and SKOV3-DDP ovarian cancer cells was $1.8,2.0$ and 2.0 , respectively. The highly lymphatic metastatic ovarian cancer cells SKOV3-PM was maintained in our laboratory, which was established and maintained as previously described (12). All of the cell lines were cultured in RPMI1640 medium, supplemented with $10 \%$ fetal bovine serum, $1 \%$ L-glutamine, $100 \mathrm{U} / \mathrm{ml}$ penicillin, $100 \mu \mathrm{g} / \mathrm{ml}$ of streptomycin, $0.25 \mu \mathrm{g} / \mathrm{ml}$ of Fungizone (Gibco, USA). The cells were cultured at $37^{\circ} \mathrm{C}$ in a humidified atmosphere containing $5 \% \mathrm{CO}_{2}$.

Real-time quantitative PCR analysis. Total RNA was isolated from cell lines, A2780, A2780-DDP, A2780-CBP, SKOV3, SKOV3-DDP and SKOV3-PM, using TRIzol reagent (Life Technologies, Carlsbad, CA, USA). The quantity and quality of RNA were measured using a Thermo Scientific NanoDrop 2000 spectrophotometer (Thermo Fisher Scientific, Wilmington, DE, USA). cDNA was synthesized from $2 \mu \mathrm{g}$ RNA with the SuperScript ${ }^{\circledR}$ III First Strand Synthesis System (Life Technologies). The mRNA levels of ALDH1A2, ADH1B, NELL2, HBB and ABCA8 were determined by Real-time quantitative PCR (RT-qPCR), which was performed with Power SYBR Green PCR Master Mix (Applied Biosystems, Life Technologies). Data were collected with the Applied Biosystems 7300 Real-time PCR System in accordance with the manufacturer's instructions.

The RT-qPCR gene-specific primers for ALDH1A2 were: (forward primer) 5'-GATGCTGACTTGGACTATGCTGT-3' and (reverse primer) 5'-CTGTTTCTTATCAATCTGGG GAC-3'; for ADH1B, the forward primer was 5'-CATTAAG ATGGTGGCTGTAGGAA-3' and the reverse primer was 5'-TTTTCAAGCAGTAGTTGCTCTCC-3'; for NELL2, the forward primer was 5'-CTTTCAAGATACTCCCAGAA GCA-3' and the reverse primer was 5'-TAAGTGGGTCTGTTT TAGGGTCA-3'; for HBB, the forward primer was 5'-CAA GGTGAACGTGGATGAAGT-3' and the reverse primer was 5'-ATAACAGCATCAGGAGTGGACAG-3'; for ABCA8, the forward primer was 5'-CACAAGAGAGAGGAAAAG GATGA-3' and the reverse primer was 5'-GGAGAAAGAGG
CTGAAGACTACC-3'. For GAPDH, used as the control, the forward primer was 5'-GAAGGTGAAGGTCGGAGT-3' and the reverse primer 5'-GAAGATGGTGATGGGATTT-3'.

Gene expression profiles. Gene expression data were retrieved from the Oncomine (https://www.oncomine.org/resource/ login.html) (13) and GEO profiles databases (http://www.ncbi. nlm.nih.gov/geoprofiles/) $(14,15)$ and cBioPortal for Cancer Genomics (http://cbioportal.org) (16,17). TCGA Ovarian Statistics, Bonome Ovarian Statistics, Yoshihara Ovarian Statistics, Lu Ovarian Statistics and Welsh Ovarian Statistics data are all deposited in Oncomine. Microarrays GDS3592, GDS3297, GDS2785 and GDS3894 are all deposited in GEO profiles. In Oncomine, for the purpose of whole study analysis, P-values are corrected for multiple comparisons by the method of false discovery rates (13). In regard to an independent array, the differentially expressed genes between cancers and normal controls are ranked by P-value (the gene with smallest P-value is ranked number 1). The top 500 up- and down-regulated genes with the smallest P-values from the TCGA Ovarian Statistics data were retrieved for further analysis. In the GEO profiles database, only one probe set with significant variability in statistics was retained when there were two probe sets targeting one gene. When there were more than three probe sets targeting one gene, the set exhibiting the most divergent expression would first be excluded, and then the set with significant variability in statistics was retained. The clinical data of 489 cases of ovarian carcinoma with gene expression value in TCGA datasets was retrieved from the cBioPortal for Cancer Genomics $(16,17)$.

Bioinformatics analyses. Enrichment of the biological processes of a group of genes was performed using the DAVID online tool (http://david.abcc.ncifcrf.gov/) $(18,19)$. Annotation of biological processes with genes was performed using the Coremine Medical online database (http://www.coremine. $\mathrm{com} /$ medical/) (20). The protein/gene-protein/gene interaction analysis was performed using the GeneMANIA online tool (http://www.genemania.org/) $(21,22)$.

Data analysis. The data were analyzed by SPSS 20.0 software. The mRNA expression of a gene is presented as means \pm SD. The measurement data were analyzed using one-way ANOVA. Homogeneity of the variances was analyzed using the t-test. The probability of survival and significance was calculated using the Kaplan-Meier method and log-rank test. Expression values of a gene were dichotomized into high and low expression using the median as a cutoff for Kaplan-Meier analysis, in accordance with a previous study (23). P-values of $<0.05$ were considered to indicate statistically significant differences.

\section{Results}

Biological process enrichment of differentially expressed genes in ovarian serous cystadenocarcinomas. The TCGA Ovarian microarrays deposited in Oncomine (13) were selected to mine significantly expressed genes in ovarian cancer. According to the ranked P-value, the top 500 up- and down-regulated genes in 594 ovarian serous cystadenocarcinomas in comparison with eight normal ovaries were retrieved 
Table I. The 60 and 126 genes up- and down-regulated by at least 4-fold in 594 ovarian serous cystadenocarcinomas in comparison with eight normal ovaries $(\mathrm{P}<1.07 \mathrm{E}-6$ and $\mathrm{P}<1.73 \mathrm{E}-5$, respectively), according to The Cancer Genome Atlas (TCGA) Ovarian Statistics data deposited in the Oncomine database.

\begin{tabular}{|c|c|c|c|c|c|c|c|c|c|c|c|}
\hline Gene & Fold & Gene & Fold & Gene & Fold & Gene & Fold & Gene & Fold & Gene & Fold \\
\hline \multicolumn{12}{|c|}{ Upregulated genes (60) } \\
\hline TOP $2 A$ & 18.64 & $K I F 20 A$ & 9.02 & PRC1 & 7.21 & HJURP & 5.55 & BIRC5 & 4.83 & ZWILCH & 4.33 \\
\hline$T T K$ & 15.15 & $C D K N 3$ & 8.28 & $T F A P 2 A$ & 7.19 & COLIAI & 5.49 & CCNA2 & 4.79 & $M A D 2 L 1$ & 4.33 \\
\hline$T P X 2$ & 13.89 & $D L G A P 5$ & 8.15 & CCNE1 & 7.06 & KIF 11 & 5.47 & NCAPD2 & 4.76 & $A P O B E C 3 B$ & 4.32 \\
\hline PRAME & 12.32 & CEP55 & 8.07 & $R A C G A P 1$ & 6.67 & $B U B 1$ & 5.27 & MCM4 & 4.73 & $L O X L 2$ & 4.31 \\
\hline CENPA & 11.78 & $B U B 1 B$ & 8.04 & $A U R K A$ & 6.5 & CHODL & 5.26 & MEST & 4.71 & TRIB3 & 4.28 \\
\hline$M E L K$ & 10.6 & $A T A D 2$ & 7.78 & $C D K N 2 A$ & 6.48 & STIL & 5.1 & APOAI & 4.68 & $C K A P 2$ & 4.26 \\
\hline ECT2 & 10.21 & COL11A1 & 7.66 & NDC80 & 6.17 & $T M E F F 1$ & 5.08 & $C R A B P 1$ & 4.56 & CHEK1 & 4.15 \\
\hline$U B E 2 C$ & 10.18 & $K P N A 2$ & 7.57 & $D T L$ & 6.09 & $T K 1$ & 4.97 & FANCI & 4.43 & OIP5 & 4.12 \\
\hline$N M U$ & 10.11 & SMC4 & 7.44 & FOXM1 & 5.98 & KIF $1 A$ & 4.91 & ESPL1 & 4.34 & MKI67 & 4.02 \\
\hline NUSAP1 & 9.73 & $C D K 1$ & 7.32 & $P T H 2 R$ & 5.58 & $C D C A 3$ & 4.85 & $C D C 7$ & 4.33 & $G B P 1$ & 4 \\
\hline \multicolumn{12}{|c|}{ Downregulated genes (126) } \\
\hline CRISP3 & -226.52 & $H B B$ & -19.22 & ZMYND10 & -13.05 & $I G F B P 6$ & -10.67 & BCHE & -8.39 & REEPI & -7.04 \\
\hline OVGPI & -102.95 & ТРPP3 & -18.87 & $T F F 3$ & -13.02 & FABP6 & -9.28 & $S L C 27 A 2$ & -8.11 & CLDN10 & -7.04 \\
\hline C6 & -58.08 & $L R R C 48$ & -17.59 & C4orf31 & -12.98 & $P L N$ & -9.28 & $T F P I$ & -7.98 & HOXB6 & -7.03 \\
\hline$A G R 2$ & -44.39 & NXF3 & -17.37 & $E F C A B 1$ & -12.49 & SYNE1 & -9.23 & LYVE1 & -7.82 & RTN1 & -7 \\
\hline MYH11 & -44.34 & $A B C A 8$ & -16.55 & PTPRN2 & -12.13 & SLC27A6 & -9.22 & $C C D C 81$ & -7.79 & CCDC69 & -6.98 \\
\hline$A L D H 1 A 2$ & -36.01 & $M A O A$ & -15.71 & LRRC50 & -12.03 & $P A X 2$ & -9.03 & C6orf97 & -7.61 & C9orf116 & -6.87 \\
\hline SPAG6 & -24.91 & $H B A 1$ & -15.01 & CCL14 & -11.86 & HOXA5 & -8.9 & CLEC $3 B$ & -7.59 & PTGIS & -6.84 \\
\hline$A D H 1 B$ & -23.12 & $Z B B X$ & -13.92 & $M A O B$ & -11.81 & NME5 & -8.82 & SPA17 & -7.57 & CNN1 & -6.81 \\
\hline NELL2 & -22.31 & $P A C R G$ & -13.85 & $A L D H I A l$ & -11.74 & KCNJ2 & -8.58 & TSPAN1 & -7.19 & $P P P 2 R 2 B$ & -6.58 \\
\hline$H B A 2$ & -22.08 & PLAC8 & -13.78 & SFRP1 & -11.71 & DNAII & -8.52 & EFEMP1 & -7.15 & C14orf45 & -6.52 \\
\hline DNAI2 & -21.47 & DNAH9 & -13.52 & CCL21 & -11.34 & $N B E A$ & -8.43 & EFHC2 & -7.13 & Clorf114 & -6.5 \\
\hline ACTG2 & -19.37 & SFRP4 & -13.25 & $L R R C 23$ & -10.69 & $C F D$ & -8.43 & DNAH7 & -7.07 & $F C G B P$ & -6.48 \\
\hline$P D E 8 B$ & -6.45 & $H N F 1 B$ & -5.78 & COX7A1 & -5.24 & $M A P I A$ & -4.71 & $B C L 2$ & -4.47 & $T B X 2$ & -4.2 \\
\hline$S L C 24 A 3$ & -6.43 & CHN2 & -5.77 & SOCS 2 & -5.16 & $M G L L$ & -4.69 & $I T M 2 A$ & -4.45 & $V W A 5 A$ & -4.18 \\
\hline SPARCLI & -6.4 & $D L C 1$ & -5.69 & $D C N$ & -5.13 & ZFPM2 & -4.65 & CWH43 & -4.42 & $N P D C 1$ & -4.17 \\
\hline$C C N D 2$ & -6.39 & LOC100289175 & -5.59 & CPA3 & -5.04 & $N D N$ & -4.62 & LAMA2 & -4.37 & $N R 2 F 1$ & -4.16 \\
\hline PRUNE2 & -6.39 & AMIGO2 & -5.59 & EPB41L3 & -5.04 & ATXN10 & -4.62 & $K I F 4 C P$ & -4.32 & TMEM47 & -4.12 \\
\hline$F R Y$ & -6.35 & $A K 1$ & -5.56 & FAM107A & -5.03 & FAM149A & -4.58 & SOD3 & -4.32 & ACTA2 & -4.09 \\
\hline OSR2 & -6.27 & $L R P 2 B P$ & -5.48 & $D M D$ & -5.02 & SATB 1 & -4.53 & $P P A P 2 C$ & -4.26 & LRRC49 & -4.06 \\
\hline CYP1B1 & -5.97 & $A K R 1 C 3$ & -5.42 & $E N P P 2$ & -4.96 & SORBS2 & -4.51 & DZIP3 & -4.26 & GPRASP1 & -4.03 \\
\hline EFHCl & -5.84 & $I G F B P 4$ & -5.29 & $T N X B$ & -4.83 & $T A C C 1$ & -4.49 & RNASE4 & -4.23 & PLCL2 & -4.01 \\
\hline
\end{tabular}

for further analysis $(P<1.07 E-6$ and $P<1.73 E-5$, respectively). Among these, 60 and 126 genes were up- and down-regulated by at least 4-fold, respectively (the list of 186 genes is shown in Table I). These 186 genes were submitted to biological process enrichment using DAVID $(18,19)$. As shown in Table II, the two highly-enriched clusters covered a total of 15 biological processes. Cluster 1 included 12 biological processes, which all were cell cycle-related, and cluster 2 included three biological processes, which all were microtubule-related. Cell cycle- and microtubule-related processes covered a total of 40 genes and 24 genes, respectively. These results indicated that microtubules and the cell cycle, in particular the latter, might play crucial roles in ovarian cancer development and progression.
Six genes are significantly downregulated by at least 10-fold in ovarian cancers. Among the 60 and 126 genes that were up- and down-regulated by at least 4-fold in ovarian serous cystadenocarcinoma, nine and 37 were up- and down-regulated by at least 10 -fold, respectively (Table I). The expression of these 46 genes was confirmed by Bonome Ovarian Statistics, which covered 185 cases of ovarian carcinomas and 10 cases of normal ovarian surface epitheliums. As shown in Table III, six genes including aldehyde dehydrogenase 1 family, member A2 (ALDH1A2), alcohol dehydrogenase 1B (class I), $\beta$ polypeptide $(A D H 1 B)$, NEL-like 2 (chicken) (NELL2), hemoglobin, $\beta$ $(H B B)$, ATP-binding cassette, sub-family A (ABC1), member 8 (ABCA8) and hemoglobin, $\alpha 1$ (HBAl) were downregulated by at least 10-fold in both the TCGA Ovarian Statistics and Bonome 
Table II. Biological process enrichment of 186 genes differentially expressed by at least 4-fold in ovarian serous cystadenocarcinomas using DAVID.

\begin{tabular}{|c|c|c|c|}
\hline Enriched biological processes & P-value & Benjamini & No. of genes \\
\hline \multicolumn{4}{|c|}{ Cell cycle-related biological processes (40 in total) } \\
\hline Mitotic cell cycle & $7.2 \mathrm{E}-18$ & $9.7 \mathrm{E}-15$ & 31 \\
\hline Cell cycle phase & $1.8 \mathrm{E}-17$ & $1.2 \mathrm{E}-14$ & 32 \\
\hline Cell cycle process & $3.2 \mathrm{E}-16$ & $1.5 \mathrm{E}-13$ & 35 \\
\hline Cell cycle & $7.1 \mathrm{E}-16$ & $2.3 \mathrm{E}-13$ & 40 \\
\hline Cell division & $1.8 \mathrm{E}-13$ & $5.0 \mathrm{E}-11$ & 24 \\
\hline M phase & $2.2 \mathrm{E}-13$ & $5.1 \mathrm{E}-11$ & 25 \\
\hline Nuclear division & $4.5 \mathrm{E}-12$ & $8.7 \mathrm{E}-10$ & 20 \\
\hline Mitosis & $4.5 \mathrm{E}-12$ & $8.7 \mathrm{E}-10$ & 20 \\
\hline M phase of mitotic cell cycle & $6.2 \mathrm{E}-12$ & $1.1 \mathrm{E}-9$ & 20 \\
\hline Organelle fission & $9.2 \mathrm{E}-12$ & $1.4 \mathrm{E}-9$ & 20 \\
\hline Regulation of mitotic cell cycle & $1.4 \mathrm{E}-8$ & $1.9 \mathrm{E}-6$ & 14 \\
\hline Regulation of cell cycle & $1.7 \mathrm{E}-7$ & $1.9 \mathrm{E}-5$ & 18 \\
\hline \multicolumn{4}{|c|}{ Microtubule-related biological processes ( 24 in total) } \\
\hline Microtubule-based process & $1.5 \mathrm{E}-7$ & $1.8 \mathrm{E}-5$ & 16 \\
\hline Cytoskeleton organization & $1.7 \mathrm{E}-6$ & $1.5 \mathrm{E}-4$ & 19 \\
\hline Microtubule cytoskeleton organization & $5.7 \mathrm{E}-6$ & $3.7 \mathrm{E}-4$ & 11 \\
\hline
\end{tabular}

Ovarian Statistics data. Moreover, $A D H 1 B, H B B, A B C A 8$ and $H B A 1$ were downregulated by at least 10 -fold in 43 cases of ovarian serous adenocarcinoma compared with 10 samples of peritoneum, according to the Yoshihara Ovarian Statistics data. In addition, $H B B$ was downregulated by 27.423 -fold in 20 cases of ovarian serous adenocarcinoma compared with five cases of ovarian surface epithelium according to Lu Ovarian Statistics, and downregulated by 16.061 -fold in 28 cases of ovarian serous surface papillary carcinoma compared with four ovaries according to Welsh Ovarian Statistics. The results above indicated that $A L D H 1 A 2, A D H 1 B, N E L L 2, H B B$, $A B C A 8$ and $H B A l$ were stably and strongly downregulated in ovarian cancers, suggested that these genes might play critical roles in ovarian cancer progression.

The mRNA expression of these six genes in ovarian cancer cells was examined on the basis of microarray data (GDS3592) retrieved from the GEO online database. As shown in Fig. 1, with the exception of $H B A 1$, the other five genes were all downregulated in ovarian cancer epithelial cells compared with ovarian normal surface epithelial; in particular, the expression of $A L D H 1 A 2, A D H 1 B$ and $A B C A 8$ was downregulated by at least 2-fold in cancer cells. The coding sequences of $H B A I$ and $H B A 2$ are identical, as described in the summary of $H B A I$ (NCBI Gene ID: 3039), thus the expression status of $H B A I$ was not determined.

Potential roles of the six genes in ovarian cancer. We used the Coremine Medical online database/tool (20) to further analyze the potential roles of the six identified genes in ovarian cancer. On the basis of the direct relations between the genes in ovarian cancer (Fig. 2), $A L D H 1 A 2, H B B, A B C A 8$ and $H B A 1$ might be associated with prognosis in ovarian cancer, while $A L D H 1 A 2, H B B, A B C A 8$ and $H B A 1$ might be associated with

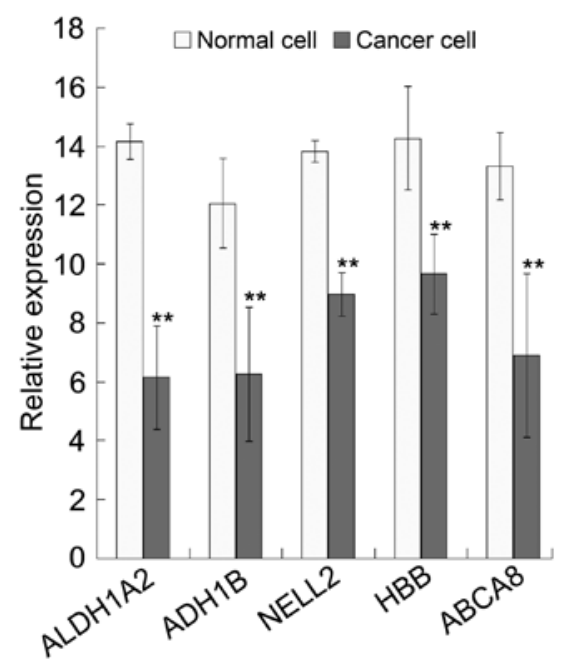

Figure 1. mRNA expression of five genes in ovarian normal surface epithelia and ovarian cancer epithelial cells in accordance with microarray data (GDS3592) retrieved from Gene Expression Omnibus (GEO). Normal ovarian surface epithelial cells were collected from ovaries at the time of surgery using a Cytobrush Plus; tumor tissues were surgically removed and collected for cell isolation (24). Twelve biological replicates were performed for normal and tumor cells. ${ }^{* *} \mathrm{P}<0.01$.

drug resistance, and $H B B$ and $H B A 1$ might be associated with recurrence, metastasis and invasiveness in ovarian cancer.

The correlation of $H B B$ with prognosis in ovarian cancer was supported by an analysis of $H B B$ expression in 20 patients with stage III serous ovarian adenocarcinomas who survived more than 5 years and 34 patients who died within 5 years, in accordance with microarray data (GDS3297) retrieved from GEO (25). $H B B$ mRNA expression was significantly increased 
Table III. Six genes were downregulated by at least 10 -fold in ovarian cancers compared with normal controls in accordance with three independent microarray datasets.

\begin{tabular}{|c|c|c|c|c|c|c|}
\hline \multirow[b]{2}{*}{ Gene } & \multicolumn{2}{|c|}{$\begin{array}{l}\text { TCGA Ovarian Statistics } \\
\text { (8 normal vs. } 594 \text { cancers) }\end{array}$} & \multicolumn{2}{|c|}{$\begin{array}{l}\text { Bonome Ovarian Statistics } \\
\text { (10 normals vs. } 195 \text { cancers) }\end{array}$} & \multicolumn{2}{|c|}{$\begin{array}{l}\text { Yoshihara Ovarian Statistics } \\
\text { (10 normals vs. } 53 \text { cancers) }\end{array}$} \\
\hline & P-value & Fold-change & P-value & Fold-change & P-value & Fold-change \\
\hline$A L D H 1 A 2$ & $9.06 \mathrm{E}-21$ & 36.01 & $2.80 \mathrm{E}-11$ & 21.374 & $>0.05$ & \\
\hline$A D H I B$ & $2.26 \mathrm{E}-07$ & 23.12 & $3.66 \mathrm{E}-05$ & 11.965 & 4.13E-07 & 24.248 \\
\hline NELL2 & $2.58 \mathrm{E}-07$ & 22.31 & $1.95 \mathrm{E}-09$ & 13.335 & $>0.05$ & \\
\hline$H B B$ & $6.72 \mathrm{E}-07$ & 19.22 & $5.14 \mathrm{E}-05$ & 17.762 & $9.76 \mathrm{E}-14$ & 33.621 \\
\hline$A B C A 8$ & $2.55 \mathrm{E}-06$ & 16.55 & $3.30 \mathrm{E}-15$ & 18.641 & $5.87 \mathrm{E}-06$ & 14.364 \\
\hline$H B A l$ & $4.27 \mathrm{E}-08$ & 15.01 & $3.05 \mathrm{E}-05$ & 12.332 & $1.43 \mathrm{E}-07$ & 51.921 \\
\hline
\end{tabular}

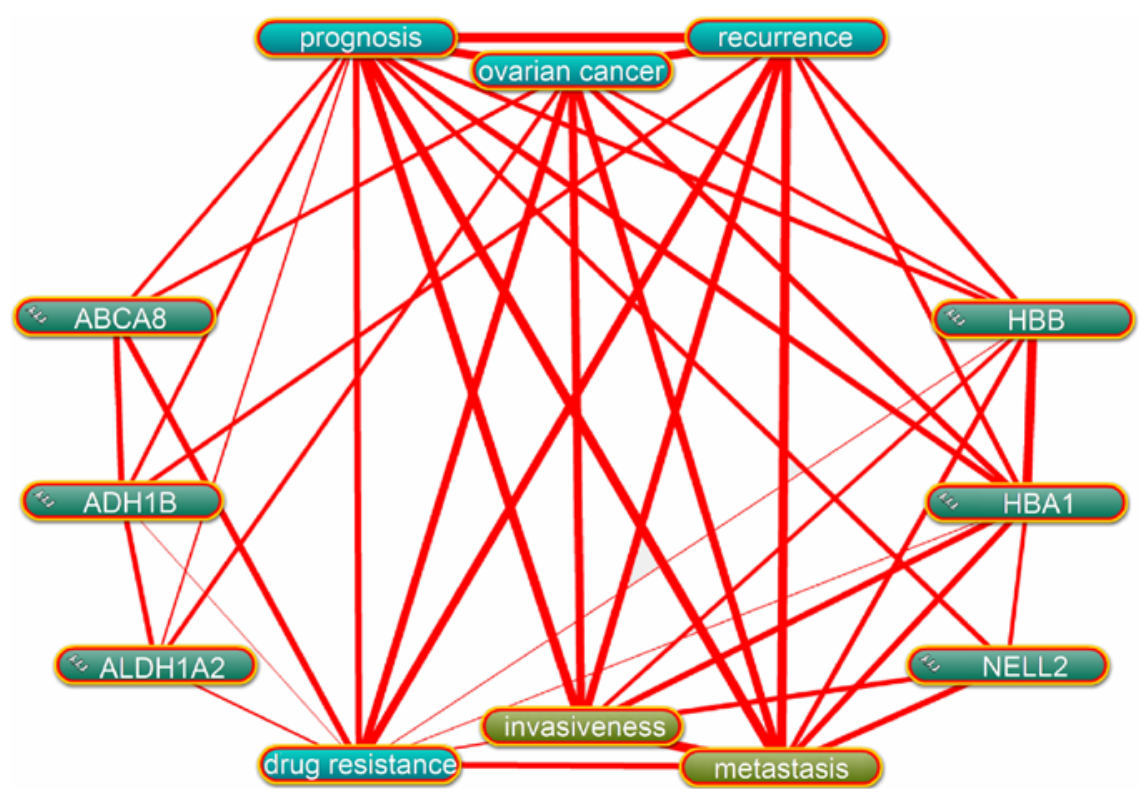

Figure 2. Function prediction and analysis of the six identified genes in ovarian cancer using the Coremine Medical online tool. The thickest red line indicates the strongest association.

by 3.39-fold in 34 ovarian cancer patients who died within 5 years (Fig. 3). As shown in Table IV, ANOVA test indicated that only $H B B$ exhibited a significant difference between the two groups. These results revealed that high expression of HBB might affect the prognosis of patients with stage III serous ovarian adenocarcinomas.

The correlation of $A L D H 1 A 2$ and $A B C A 8$ with prognosis in ovarian cancer was supported by analysis of their expression with overall survival time on the basis of TCGA clinical data. A total of 557 TCGA ovarian cancer patient samples with clinical data were retrieved from cBioPortal for Cancer Genomics (http://cbioportal.org) (16,17). Among those, 489 samples with mRNA expression value were selected for analysis the relationship of each gene expression with survival time. The expression values of a gene were categorized high or low by the median value in accordance with a previous study (23). The associations of $A L D H 1 A 2, A D H 1 B, N E L L 2, H B B$ and $A B C A 8$ with disease free status and overall survival were analyzed using the Kaplan-Meier. As shown in Fig. 4, among the 5 genes, the high expression of $A L D H 1 A 2$ and $A B C A 8$ predicted a

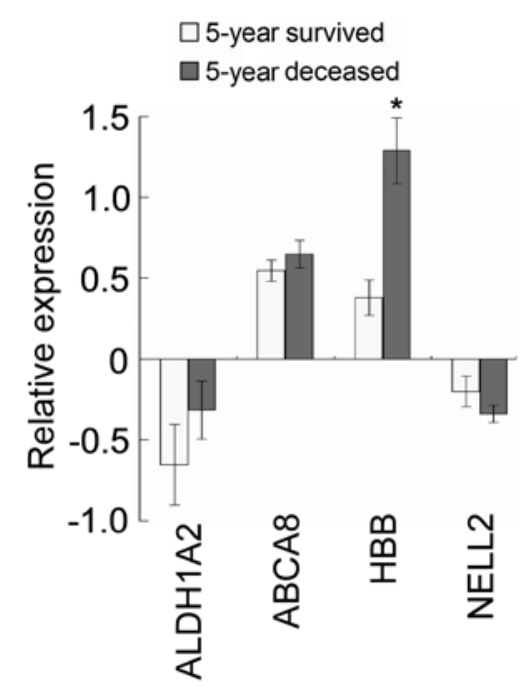

Figure 3. $H B B$ mRNA expression in 20 ovarian cancer patients who survived more than 5 years and 34 patients who died within 5 years, in accordance with microarray data (GDS3297) retrieved from Gene Expression Omnibus (GEO). " $\mathrm{P}<0.05$. 

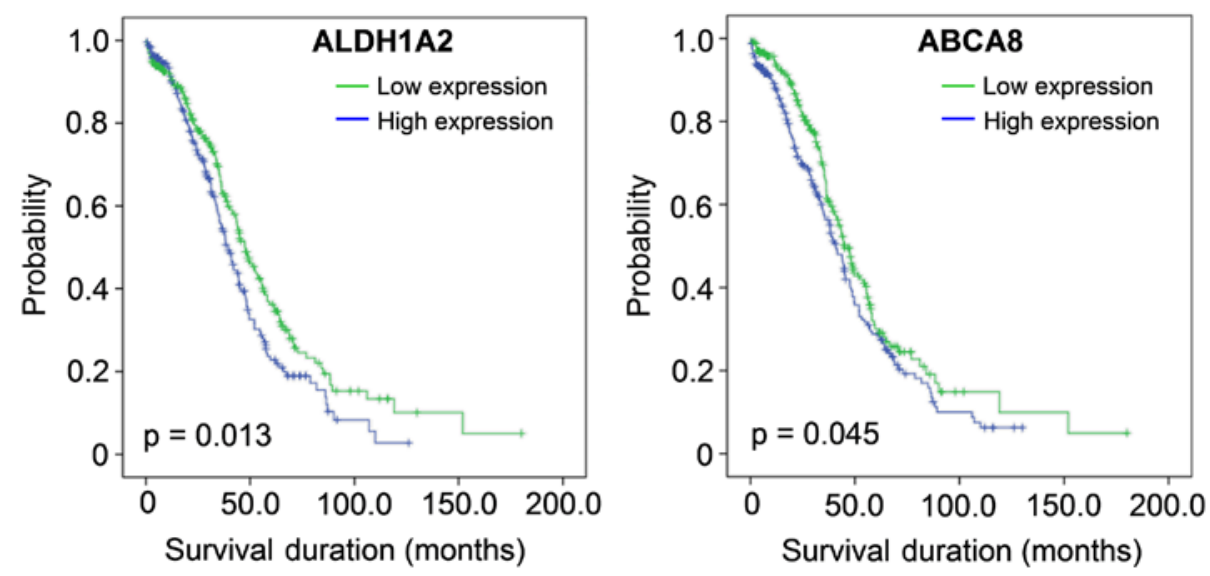

Figure 4. Kaplan-Meier survival plots for $A L D H 1 A 2$ and $A B C A 8$. The overall survival of 489 ovarian cancer patients was used for the survival analysis. Expression values of a gene were dichotomized into high and low expression using the median as a cutoff. Green line: low expression and blue line: high expression.
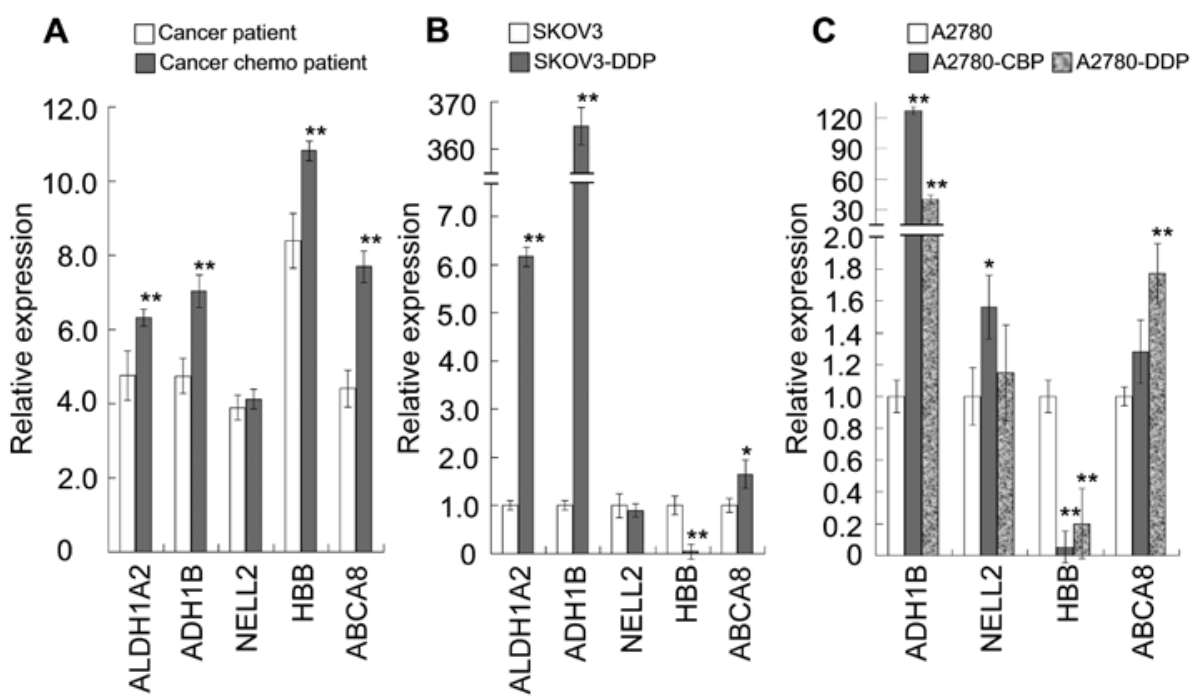

Figure 5. mRNA expression levels of the 5 genes in chemotherapy-treated ovarian cancer patients and drug-resistant cells. (A) mRNA expression in 9 ovarian cancer patients and 24 chemotherapy-treated cancer patients, in accordance with microarray data (GDS2785) retrieved from Gene Expression Omnibus (GEO). (B) mRNA expression in SKOV3 and cisplatin-resistant SKOV3-DDP cells (4 biological replicates each). (C) mRNA expression in A2780, cisplatin-resistant A2780-DDP and carboplatin-resistant A2780-CBP cells (4 biological replicates each). ${ }^{* *} \mathrm{P}<0.01,{ }^{*} \mathrm{P}<0.05$.

poor prognosis $(39.400 \pm 2.202$ vs. $47.600 \pm 2.884$ months, and $41.000 \pm 2.427$ vs. $45.100 \pm 2.476$ months, respectively).

The association of $A L D H 1 A 2, H B B$ and $A B C A 8$ with drug resistance was further supported by RT-qPCR analysis and a gene expression analysis in 9 adenocarcinomas from ovarian cancer patients not pre-treated with chemotherapy prior to surgery and 24 adenocarcinomas from patients treated with chemotherapy, in accordance with microarray data (GDS2785) retrieved from GEO (26). As shown in Fig. 5A, mRNA expression of $A L D H 1 A 2, A D H 1 B, H B B$ and $A B C A 8$ was significantly increased in ovarian cancer patients after chemotherapy in comparison with patients who did not receive chemotherapy. The RT-qPCR results indicated that the expression of $A L D H 1 A 2, A D H 1 B$ and $A B C A 8$ were significantly upregulated in SKOV3-DDP cells, $A D H 1 B$ and $A B C A 8$ were significantly upregulated in A2780-DDP and -CBP cells, consistent with their expression according to microarray data (GDS2785), although the expression of ALDH1A2 was not detected in A2780 and its drug-resistant cells, and the opposite expression profiles of $H B B$ were acquired (Fig. 5B and $C$ ). In particular, the expression of $A L D H 1 A 2$ and $A D H 1 B$ was extremely highlighted in drug-resistant cells. These results suggested that the four genes might be involved in drug resistance in ovarian cancer.

Protein/gene interaction networks indicated that the four genes directly or indirectly interacted with 15 drug resistance-related tumor suppressor genes (TSGs) (27) and 25 oncogenes (28) in ovarian cancer, via co-expression, co-localization, genetic interactions, physical interactions, shared common pathways and protein domains (Fig. 6), indicating a functional relationship (27,28). Among the 40 genes, $A L D H 1 A 2$ directly interacted with nine genes/ proteins including $\mathrm{WW}$ domain containing oxidoreductase $(W W O X)$, Kirsten rat sarcoma viral oncogene homolog $(K R A S)$, jun proto-oncogene $(J U N)$, BCL2-associated X protein $(B A X)$, ninein-like $(N I N L)$, signal transducer and 


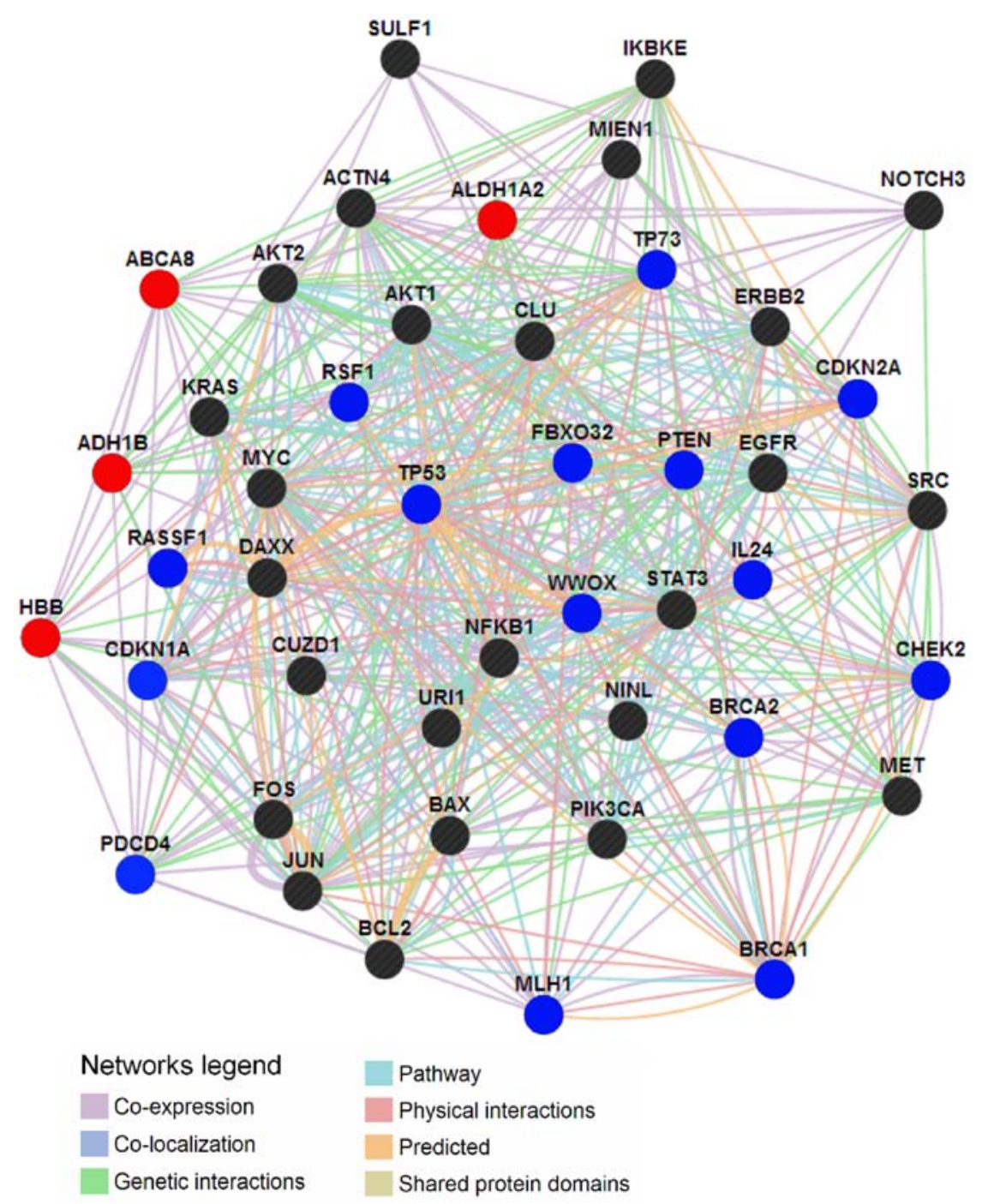

Figure 6. Protein/gene interaction network of four genes/proteins (ALDH1A2, ADH1B, HBB and ABCA8) with 15 TSGs (27) and 25 oncogenes (28) associated with drug resistance in ovarian cancer. The network was generated using the GeneMania tool. The networks legend indicates the types of interactions between genes/proteins. The queries in red indicate the target genes/proteins, those in blue indicate the TSGs, and the black are the oncogenes.

activator of transcription 3 (acute-phase response factor) (STAT3), MET proto-oncogene, receptor tyrosine kinase $(M E T)$, v-erb-b2 avian erythroblastic leukemia viral oncogene homolog 2 (ERBB2) and notch 3 (NOTCH3); ADH1B directly interacted with 12 genes/proteins including programmed cell death 4 (neoplastic transformation inhibitor) (PDCD4), F-box protein 32 (FBXO32), phosphatase and tensin homolog (PTEN), tumor protein p73 (TP73), sulfatase 1 (SULF1), FBJ murine osteosarcoma viral oncogene homolog (FOS), JUN, $M E T$, clusterin (CLU), ERBB2, actinin, $\alpha 4$ (ACTN4) and v-akt murine thymoma viral oncogene homolog 2 (AKT2); ABCA8 directly interacted with 10 genes/proteins including $P D C D 4$, breast cancer 2, early onset (BRCA2), TP73, FOS, CUB and zona pellucida-like domains 1 (CUZD1), prefoldin-like chaperone (URI1), nuclear factor of kappa light polypeptide gene enhancer in B-cells 1 (NFKB1), epidermal growth factor receptor $(E G F R), C L U$ and inhibitor of kappa light polypeptide gene enhancer in B-cells, kinase epsilon (IKBKE); and $H B B$ directly interacted with 12 genes/proteins including $P D C D 4$, FOS, JUN, B-cell CLL/lymphoma 2 (BCL2), URI1, NINL, $B R C A 2, N F K B 1, E G F R, C L U$, v-akt murine thymoma viral oncogene homolog $1(A K T 1)$ and $A K T 2$. These results suggested that the four genes and their directly interacting genes/proteins might be critically related in function. Particularly, ALDH1A2 exhibited genetic interactions with $B A X$. BAX is downstream of oncogene-mediated drug resistance pathways with respect to 22 oncogenes, and plays central roles in the regulation of drug resistance in ovarian cancer (28). Moreover, $A D H 1 B, H B B$ and $A B C A 8$ all were co-expressed with $C L U, F O S$ and $P D C D 4$, all of which are important regulators of drug resistance in ovarian cancer. For example, PDCD4 is a TSG that can promote cisplatin-induced apoptosis, mainly by activating the death receptor pathway, and $P D C D 4$ gene transfer in combination with cisplatin therapy may reverse the chemotherapeutic resistance of ovarian cancer cells (29). Additionally, ALDH1A2, $A D H 1 B, H B B$ and $A B C A 8$ were all co-expressed according to the interaction network (Fig. 6). All these results supported the opinion that $A L D H 1 A 2, A D H 1 B, H B B$ and $A B C A 8$ might contribute to drug resistance in ovarian cancer.

$A L D H 1 A 2, N E L L 2, H B B$ and $A B C A 8$ might be associated with invasiveness and metastasis in ovarian cancer. Mouse ovarian surface epithelial (MOSE) cells at various stages (early 

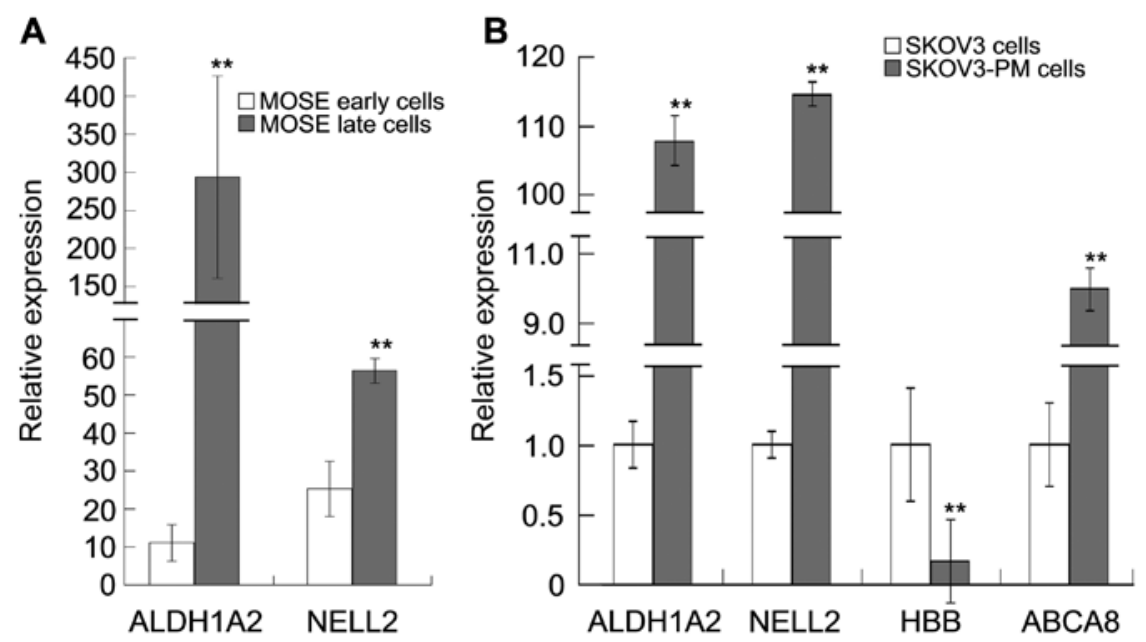

Figure 7. mRNA expression of genes in malignant/invasive and highly metastatic ovarian cancer cells. (A) mRNA expression in MOSE model of ovarian cancer cells based on microarray data (GDS3894) retrieved from Gene Expression Omnibus (GEO). The MOSE early cells were in a pre-neoplastic/nonmalignant state, and the MOSE late cells were in a malignant/invasive state (30). (B) mRNA expression in SKOV3 and highly lymphatic metastatic SKOV3-PM cells (4 biological replicates each). ${ }^{* *} \mathrm{P}<0.01$.

Table IV. ANOVA test of gene differences in surviving and deceased ovarian cancer patients at 5 years.

\begin{tabular}{lrrrrr}
\hline Gene & $\begin{array}{r}\text { Sum of } \\
\text { squares }\end{array}$ & df & $\begin{array}{r}\text { Mean } \\
\text { square }\end{array}$ & F & Sig. \\
\hline ALDH1A2 & & & & & \\
Between groups & 0.774 & 1 & 0.774 & 0.68 & 0.415 \\
Within groups & 56.128 & 49 & 1.145 & & \\
$\quad$ Total & 56.902 & 50 & & & \\
NELL2 & & & & & \\
Between groups & 0.247 & 1 & 0.247 & 2 & 0.163 \\
Within groups & 6.423 & 52 & 0.124 & & \\
Total & 6.671 & 53 & & & \\
HBB & & & & & \\
Between groups & 7.154 & 1 & 7.154 & 6.9 & 0.012 \\
Within groups & 38.344 & 37 & 1.036 & & \\
Total & 45.499 & 38 & & & \\
ABCA8 & & & & & \\
Between groups & 0.123 & 1 & 0.123 & 0.65 & 0.426 \\
Within groups & 9.374 & 49 & 0.191 & & \\
Total & 9.498 & 50 & & & \\
\hline
\end{tabular}

$A D H 1 B$ expression was only detected in a few patients, and the data was therefore not sufficient for statistical analysis.

and late) as they transition from a pre-neoplastic/non-malignant state to a malignant/invasive state provide a useful model (30). As shown in Fig. 7A, on the basis of microarray data from the MOSE model of ovarian cancer cells (GDS3894) retrieved from GEO, the mRNA expression of ALDH1A2 and NELL2 was significantly increased in MOSE late cells compared with MOSE early cells. Besides, the expression of $A L D H 1 A 2$, $N E L L 2, H B B$ and $A B C A 8$ were significantly dysregulated in highly lymphatic metastatic ovarian cancer cells (Fig. 7B), and the extremely high expression of ALDH1A2 and NELL2 was consistent with their expression in MOSE late cells. These results suggested that dysregulation of those genes, particularly the upregulation of $A L D H 1 A 2$ and NELL2 probably contributed to ovarian cancer invasiveness and metastasis.

\section{Discussion}

Oncomine is a cancer microarray database and web-based data-mining platform aimed at facilitating discovery from genome-wide expression analyses (13). Oncomine currently contains 715 datasets comprising 86,733 samples, in which 43 ovarian cancer microarray datasets are included (accessed on May 29,2014). TCGA Ovarian statistics is an ovarian cancer microarray dataset collated by Oncomine. TCGA research network completed an ovarian cancer study and released the dataset to the public, which includes thousands of microarray datasets from more than 500 ovarian tumor samples (31). Thus, this data portal provides a great platform for researchers to search, download, and the analysis of data generated by TCGA. TCGA data have been used to study the chemotherapy response (7), associations between germline genotype and survival (32), gene-gene interactions (33) and microRNA analysis (34) in ovarian cancer. Therefore, in this study, the TCGA data were used to retrieve the most dysregulated genes in ovarian cancer.

GEO Profiles is an international public repository for high-throughput microarray and next-generation sequence functional genomic datasets submitted by the research community. By 2012, the GEO database hosted $>32,000$ public series (study records) submitted directly by 13,000 laboratories, comprising 800,000 samples derived from $>1,600$ organisms (35). The datasets submitted to GEO are often in compliance with grant or journal directives that require data to be made publicly available in a MIAME-supportive (36) database. As a result, GEO has supporting data and links to almost 20,000 published manuscripts (35). In this study, the four microarray datasets used for the measurement of the 


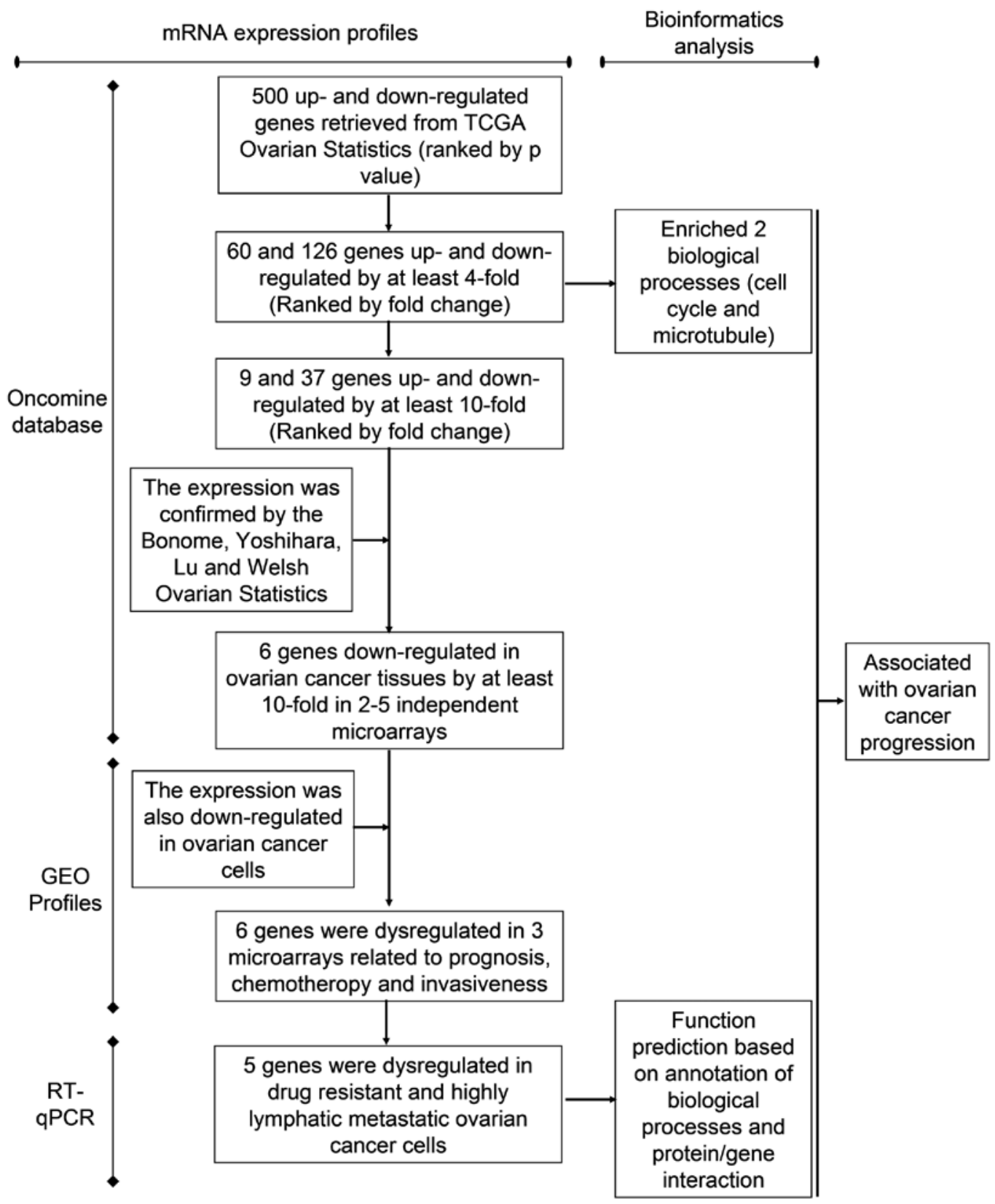

Figure 8. Procedure for identification of biological processes and genes associated with ovarian cancer progression. mRNA expression profiles were retrieved from a total of nine independent microarrays deposited in Oncomine and Gene Expression Omnibus (GEO).

six genes expression all were in compliance with published papers: GDS3592 (24), GDS3297 (25), GDS2785 (26) and GDS3894 (30).

Cancer is frequently considered to be a disease of the cell cycle as alterations in different families of cell cycle regulators cooperate in tumor development. Molecular analysis of human tumors has shown that cell cycle regulators are frequently mutated in human neoplasms, which underscores how important the maintenance of cell cycle commitment is in the prevention of human cancer (37). Dysregulation of cell cycle control, in particular G1-S-phase transition, is implicated in the pathogenesis of most human cancers, including epithelial ovarian cancer. The regulatory pathways controlling cell cycle phases include several oncogenes and TSGs that display a range of abnormalities with potential usefulness as treatment responses in epithelial ovarian cancer (38). In this study, based on the biological process enrichment of 186 highly differential expressed genes in ovarian serous cystadenocarcinomas (Table I), we revealed that the top enriched biological process was cell cycle-related, covering 40 of the catalogued 186 genes (Table II). These results indicated a central role of cell cycle in ovarian cancer progression and development, and aberrant expression of cell cycle genes is a potential target of therapy and earlier diagnostic markers (37,38).

Six genes, $A L D H 1 A 2, A D H 1 B, N E L L 2, H B B, A B C A 8$ and $H B A 1$, were downregulated by at least 10 -fold in ovarian cancers according to the TCGA Ovarian Statistics and Bonome Ovarian Statistics microarray data, which cover 594 ovarian serous cystadenocarcinomas in comparison with eight normal ovaries, and 185 ovarian carcinomas in comparison with 10 ovarian surface epitheliums, respectively (Table III). $A D H 1 B$, $H B B, A B C A 8$ and $H B A l$ were also downregulated by at least 
10-fold in other microarrays retrieved from Oncomine. Due to their stable and strong downregulation in ovarian cancers, we concluded that the six genes are potential candidates for early diagnosis and prognosis. This conclusion agreed with our findings for $A L D H 1 A 2, H B B$ and $A B C A 8$. Compared with the expression of 20 surviving ovarian cancer patients at 5 years and 34 deceased ovarian cancer patients at 5 years, the high expression of $H B B$ indeed predicted a poor 5-year survival (Fig. 3 and Table IV), and the high expression of $A L D H 1 A 2$ and $A B C A 8$ predicted a poor outcome (Fig. 4). This conclusion is also consistent with previous studies reporting that $H B B$ is a biomarker for early detection (39) and $A B C A 8$ is associated with poor outcome (23).

$\mathrm{HBB}$ is one of the globin chain components of haemoglobin A, whose basic function is oxygen transport (40). $H B B$ was found to be significantly downregulated in 11 anaplastic thyroid cancer cell lines, and a cell proliferation assay suggested that $H B B$ might be a novel TSG (41). Analysis of primary and post-treatment samples (12 tumor and eight normal) by the Affymetrix platform (HG U133 plus 2) identified 119 genes as differentially regulated in recurrent tumors, of which $H B B$ alone, and collagen, type V, $\alpha 1$ (COL5A1) and $H B B$ in combination, have the best predictive power for treatment response in patients with oral tongue cancer (42). In ovarian cancer, HBB protein is downregulated in sera collected from rats bearing serous ovarian carcinoma, and could be used as a diagnostic biomarker for early detection, disease monitoring and as a therapeutic target (39). $A B C A 8$ is a member of the ABCA family, which is one of the subfamilies of $\mathrm{ABC}$ transporter genes $(43,44)$. High-level expression of $A B C A 8$ in primary tumors was significantly associated with reduced survival in serous ovarian cancer patients, and the combined expression pattern of $\mathrm{ABC} 1$, member 1 (ABCA1), $\mathrm{ABC1}$, member 5 ( $A B C A 5)$, and $A B C A 8$ was associated with particularly poor outcome, independent of tumor stage or surgical debulking status (23).

The mRNA expression of $A L D H 1 A 2, A D H 1 B, H B B$ and $A B C A 8$ was increased when patients were treated with chemotherapies (Fig. 5A); RT-qPCR measurement indicated that the 4 genes were significantly dysregulated in cisplatin and carboplatin-resistant ovarian cancer cells (Fig. 5B and C), especially the $A L D H 1 A 2$ and $A D H 1 B$, were significantly upregulated. These results suggested that the four genes related to chemotreatment might associate with drug resistance in ovarian cancer. This conclusion was further supported by protein/ gene interaction analysis (Fig. 6), in which these four genes were found to directly/indirectly interact with 15 TSGs and 25 oncogenes that all play important roles in the regulation of drug resistance in ovarian cancer $(27,28)$. Consistent with our conclusions, the previous studies indicated that $A D H 1 B$ and $A B C A 8$ may be associated with drug resistance in ovarian cancer $(45,46)$. $A D H 1 B$ encodes a critical enzyme in alcohol metabolism, and may cause variations in the amount of production and/or oxidation of acetaldehyde between individuals (47).

The association of $A D H 1 B$ with cancer is mainly focused on its polymorphisms. For example, $A D H 1 B$ polymorphisms are associated with risk of head and neck (48), esophageal (49) and gastric cancer (50). In ovarian cancer, high $A D H 1 B$ expression is associated with significantly higher risk of residual disease in high-grade serous ovarian cancer, and patients with high tumoral levels may be candidates for neoadjuvant chemotherapy (45). In addition, $A D H 1 B$ is one gene in a group that encodes xenobiotic-metabolizing enzymes in pulmonary parenchyma and bronchial mucosa tissues from patients with non-small cell lung cancer (51). The presence of xenobioticmetabolizing enzymes has been proved to play a role in determining the intrinsic drug resistance of breast cancer to a variety of anti-cancer drugs $(52,53)$. These results together suggest that $A D H 1 B$ might be implicated in drug resistance in cancer. $A B C A 8$ has been proven to be a new drug transporter of the ABC-subfamily in humans (54).

In ovarian cancer, $A B C A 8$ is significantly ( $>10$-fold) increased in drug-resistant A2780 cells (55), consistent with the results in this study (Fig. 5). However, a controversial study indicated that $A B C A 8$ was significantly downregulated in methotrexate, cisplatin, doxorubicin, vincristine, topotecan and paclitaxel-resistant variant of the $\mathrm{W} 1$ ovarian cancer cell line (46). Associations of $A L D H 1 A 2$ with ovarian cancer is rare, with only one study indicating that $A L D H 1 A 2$ is a widespread stem-cell marker expressed in both ovarian surface epithelium and epithelium of oviductal fimbriae in which high-grade serous ovarian carcinomas may originate (56). However, it has been proven that $A L D H 1 A 2$ is involved in drug resistance in other cancers. ALDH1A2 encodes an enzyme responsible for the synthesis of retinoic acid, a compound with prodifferentiation properties. $A L D H 1 A 2$ is identified to be a candidate TSG in prostate cancer whose expression is induced by DNA demethylation, which is reduced in prostate tumors compared with normal prostate, and negatively correlated with tumor-free survival (57). A further study indicate that $A L D H 1 A 2$ is involved in apoptosis in bladder cancer cells (58), and has significant effects on cell proliferation and drug resistance in leukemia $(59,60)$ and lung cancer cell lines (59). A more recent study indicate that high expression of $A L D H 1 A 2$ is implicated in conveying tolerance to cisplatin in the three malignant pleural mesothelioma cell lines (61).

The mRNA expression of ALDH1A2 and NELL2 was notably increased in MOSE late cells, which are in a malignant/ invasive state, compared with MOSE early cells, which are in a pre-neoplastic/non-malignant state; increased ALDH1A2 expression was most remarkable, at approximately 30 -fold (Fig. 7A). In addition, the mRNA expression of the 2 genes was notably increased in highly lymphatic metastatic ovarian cancer cells (Fig. 7B). These results, together with de biological process annotation (Fig. 2), indicated that ALDH1A2 and NELL2 might contribute to ovarian cancer invasiveness and metastasis. The relationship of $A L D H 1 A 2$ with cancer invasiveness has not been previously reported, while the overexpression of NELL2 was shown to increase the invasive ability of ovarian cancer cells; this effect was enhanced when NELL2 and E2F transcription factor 1 (E2F1) were coexpressed (62). NELL2 also is found to be predominantly expressed in neuroblastoma and other embryonal neuroepithelial tumors (63), and participates in the proliferation, differentiation, and oncogenesis of colorectal cancer cells (64).

In summary, on the basis of bioinformatic analyses of mRNA expression profiles retrieved from the Oncomine and GEO Profiles online databases, we enriched two biological processes (cell cycle- and microtubule-related) and identified six genes (ALDH1A2, ADH1B, NELL2, HBB, ABCA8 and 
$H B A 1)$ (Fig. 8) that all were associated with ovarian cancer progression. This study contributes to the understanding of the mechanism of ovarian cancer progression, and the identified genes are potential therapeutic targets and biomarkers for diagnosis and prognosis in ovarian cancer.

\section{Acknowledgements}

This study was supported by the National Natural Science Foundation of China (Grant no. 81302283 and no. 81460397), China Postdoctoral Science Foundation (no. 2014M552535XB and no. 2014M552291), Natural Science Foundation of Guangxi (no. 2014GXNSFCA118010 and 2014GXNSFBA118155), and Youth Science Foundation of Guangxi Medical University (no. GXMUYSF201312).

\section{References}

1. Siegel R, Naishadham D and Jemal A: Cancer statistics, 2013. CA Cancer J Clin 63: 11-30, 2013.

2. Siegel R, Ma J, Zou Z and Jemal A: Cancer statistics, 2014. CA Cancer J Clin 64: 9-29, 2014

3. Sharan R, Ulitsky I and Shamir R: Network-based prediction of protein function. Mol Syst Biol 3: 88, 2007.

4. Stuart JM, Segal E, Koller D and Kim SK: A gene-coexpression network for global discovery of conserved genetic modules. Science 302: 249-255, 2003.

5. Uetz P, Giot L, Cagney G, Mansfield TA, Judson RS, Knight JR, Lockshon D, Narayan V, Srinivasan M, Pochart P, et al: A comprehensive analysis of protein-protein interactions in Saccharomyces cerevisiae. Nature 403: 623-627, 2000.

6. Phuong $\mathrm{T}$ and Nhung N: Predicting gene function using similarity learning. BMC Genomics 14 (Suppl 4): S4, 2013.

7. Hsu FH, Serpedin E, Hsiao TH, Bishop AJ, Dougherty ER and Chen Y: Reducing confounding and suppression effects in TCGA data: An integrated analysis of chemotherapy response in ovarian cancer. BMC Genomics 13 (Suppl 6): S13, 2012.

8. Liu X, Gao Y, Lu Y, Zhang J, Li L and Yin F: Upregulation of NEK2 is associated with drug resistance in ovarian cancer. Oncol Rep 31: 745-754, 2014.

9. Liu X, Gao Y, Lu Y, Zhang J, Li L and Yin F: Downregulation of NEK11 is associated with drug resistance in ovarian cancer. Int $\mathbf{J}$ Oncol 45: 1266-1274, 2014.

10. Yin F, Liu L, Liu X, Li G, Zheng L, Li D, Wang Q, Zhang W and Li L: Downregulation of tumor suppressor gene ribonuclease $\mathrm{T} 2$ and gametogenetin binding protein 2 is associated with drug resistance in ovarian cancer. Oncol Rep 32: 362-372, 2014.

11. Yin F, Liu X, Li D, Wang Q, Zhang W and Li L: Bioinformatic analysis of chemokine (C-C motif) ligand 21 and SPARC-like protein 1 revealing their associations with drug resistance in ovarian cancer. Int J Oncol 42: 1305-1316, 2013.

12. Ruan HY, Li DR, Li L, Guan X and Zhang W: Establishment of human ovarian carcinoma cell lines with directional highly lymphatic metastasis and study of their biological characteristics Zhonghua Fu Chan Ke Za Zhi 42: 482-486, 2007 (In Chinese).

13. Rhodes DR, Yu J, Shanker K, Deshpande N, Varambally R, Ghosh D, Barrette T, Pandey A and Chinnaiyan AM: ONCOMINE: A cancer microarray database and integrated data-mining platform. Neoplasia 6: 1-6, 2004.

14. Edgar R, Domrachev M and Lash AE: Gene expression omnibus: NCBI gene expression and hybridization array data repository. Nucleic Acids Res 30: 207-210, 2002.

15. Barrett $\mathrm{T}$ and Edgar R: Mining microarray data at NCBI's gene expression omnibus (GEO)*. Methods Mol Biol 338: 175-190, 2006.

16. Cerami E, Gao J, Dogrusoz U, Gross BE, Sumer SO, Aksoy BA, Jacobsen A, Byrne CJ, Heuer ML, Larsson E, et al: The cBio cancer genomics portal: An open platform for exploring multidimensional cancer genomics data. Cancer Discov 2: 401-404, 2012.

17. Gao J, Aksoy BA, Dogrusoz U, Dresdner G, Gross B, Sumer SO, Sun Y, Jacobsen A, Sinha R, Larsson E, et al: Integrative analysis of complex cancer genomics and clinical profiles using the cBioPortal. Sci Signal 6: pl1, 2013.
18. Huang W, Sherman BT and Lempicki RA: Systematic and integrative analysis of large gene lists using DAVID bioinformatics resources. Nat Protoc 4: 44-57, 2009.

19. Huang W, Sherman BT and Lempicki RA: Bioinformatics enrichment tools: Paths toward the comprehensive functional analysis of large gene lists. Nucleic Acids Res 37: 1-13, 2009.

20. de Leeuw N, Dijkhuizen T, Hehir-Kwa JY, Carter NP, Feuk L, Firth HV, Kuhn RM, Ledbetter DH, Martin CL, van Ravenswaaij-Arts CMA, et al: Diagnostic interpretation of array data using public databases and internet sources. Hum Mutat 33: 930-940, 2012.

21. Mostafavi S, Ray D, Warde-Farley D, Grouios C and Morris Q: GeneMANIA: A real-time multiple association network integration algorithm for predicting gene function. Genome Biol 9 (Suppl 1): S4, 2008.

22. Zuberi K, Franz M, Rodriguez H, Montojo J, Lopes CT, Bader GD and Morris Q: GeneMANIA prediction server 2013 update. Nucleic Acids Res 41: W115-22, 2013.

23. Hedditch EL, Gao B, Russell AJ, Lu Y, Emmanuel C, Beesley J, Johnatty SE, Chen X, Harnett P, George J, et al; Australian Ovarian Cancer Study Group: ABCA transporter gene expression and poor outcome in epithelial ovarian cancer. J Natl Cancer Inst 106: 106, 2014.

24. Bowen NJ, Walker LD, Matyunina LV, Logani S, Totten KA, Benigno BB and McDonald JF: Gene expression profiling supports the hypothesis that human ovarian surface epithelia are multipotent and capable of serving as ovarian cancer initiating cells. BMC Med Genomics 2: 71, 2009.

25. Partheen K, Levan K, Osterberg L and Horvath G: Expression analysis of stage III serous ovarian adenocarcinoma distinguishes a sub-group of survivors. Eur J Cancer 42: 2846-2854, 2006.

26. Moreno CS, Matyunina L, Dickerson EB, Schubert N, Bowen NJ, Logani S, Benigno BB and McDonald JF: Evidence that p53-mediated cell-cycle-arrest inhibits chemotherapeutic treatment of ovarian carcinomas. PLoS One 2: e441, 2007.

27. Yin F, Liu X, Li D, Wang Q, Zhang W and Li L: Tumor suppressor genes associated with drug resistance in ovarian cancer (Review). Oncol Rep 30: 3-10, 2013.

28. Liu X, Gao Y, Lu Y, Zhang J, Li L and Yin F: Oncogenes associated with drug resistance in ovarian cancer. J Cancer Res Clin Oncol 141: 381-395, 2015.

29. Zhang X, Wang X, Song X, Liu C, Shi Y, Wang Y, Afonja O, Ma C, Chen YH and Zhang L: Programmed cell death 4 enhances chemosensitivity of ovarian cancer cells by activating death receptor pathway in vitro and in vivo. Cancer Sci 101: 2163-2170, 2010.

30. Creekmore AL, Silkworth WT, Cimini D, Jensen RV, Roberts PC and Schmelz EM: Changes in gene expression and cellular architecture in an ovarian cancer progression model. PLoS One 6: e17676, 2011.

31. Cancer Genome Atlas Research Network: Integrated genomic analyses of ovarian carcinoma. Nature 474: 609-615, 2011.

32. Braun R, Finney R, Yan C, Chen QR, Hu Y, Edmonson M, Meerzaman D and Buetow K: Discovery analysis of TCGA data reveals association between germline genotype and survival in ovarian cancer patients. PLoS One 8: e55037, 2013.

33. Ying H, Lv J, Ying T, Jin S, Shao J, Wang L, Xu H, Yuan B and Yang Q: Gene-gene interaction network analysis of ovarian cancer using TCGA data. J Ovarian Res 6: 88, 2013.

34. Wan YW, Mach CM, Allen GI, Anderson ML and Liu Z: On the reproducibility of TCGA ovarian cancer microRNA profiles. PLoS One 9: e87782, 2014.

35. Barrett T, Wilhite SE, Ledoux P, Evangelista C, Kim IF, Tomashevsky M, Marshall KA, Phillippy KH, Sherman PM, Holko M, et al: NCBI GEO: Archive for functional genomics data sets - update. Nucleic Acids Res 41: D991-D995, 2013.

36. Brazma A, Hingamp P, Quackenbush J, Sherlock G, Spellman P, Stoeckert C, Aach J, Ansorge W, Ball CA, Causton HC, et al: Minimum information about a microarray experiment (MIAME)-toward standards for microarray data. Nat Genet 29: 365-371, 2001.

37. D'Andrilli G, Kumar C, Scambia G and Giordano A: Cell cycle genes in ovarian cancer: Steps toward earlier diagnosis and novel therapies. Clin Cancer Res 10: 8132-8141, 2004.

38. D'Andrilli G, Giordano A and Bovicelli A: Epithelial ovarian cancer: The role of cell cycle genes in the different histotypes. Open Clin Cancer J 2: 7-12, 2008.

39. Huang Y, Zhang X, Jiang W, Wang Y, Jin H, Liu X and Xu C: Discovery of serum biomarkers implicated in the onset and progression of serous ovarian cancer in a rat model using iTRAQ technique. Eur J Obstet Gynecol Reprod Biol 165: 96-103, 2012. 
40. Giardina B, Messana I, Scatena R and Castagnola M: The multiple functions of hemoglobin. Crit Rev Biochem Mol Biol 30: 165-196, 1995

41. Onda M, Akaishi J, Asaka S, Okamoto J, Miyamoto S, Mizutani K, Yoshida A, Ito K and Emi M: Decreased expression of haemoglobin beta (HBB) gene in anaplastic thyroid cancer and recovery of its expression inhibits cell growth. Br J Cancer 92: 2216-2224, 2005.

42. Suresh A, Vannan M, Kumaran D, Gümüs ZH, Sivadas P, Murugaian EE, Kekatpure V, Iyer S, Thangaraj K and Kuriakose MA: Resistance/response molecular signature for oral tongue squamous cell carcinoma. Dis Markers 32: 51-64, 2012.

43. Annilo T, Chen ZQ, Shulenin S and Dean M: Evolutionary analysis of a cluster of ATP-binding cassette (ABC) genes. Mamm Genome 14: 7-20, 2003.

44. Nagase T, Ishikawa K, Suyama M, Kikuno R, Hirosawa M, Miyajima N, Tanaka A, Kotani H, Nomura N and Ohara O: Prediction of the coding sequences of unidentified human genes. XII. The complete sequences of 100 new cDNA clones from brain which code for large proteins in vitro. DNA Res 5: 355-364, 1998.

45. Tucker SL, Gharpure K, Herbrich SM, Unruh AK, Nick AM, Crane EK, Coleman RL, Guenthoer J, Dalton HJ, Wu SY, et al: Molecular biomarkers of residual disease after surgical debulking of high-grade serous ovarian cancer. Clin Cancer Res 20: 3280-3288, 2014.

46. Januchowski R, Zawierucha P, Andrzejewska M, Ruciński M and Zabel M: Microarray-based detection and expression analysis of $\mathrm{ABC}$ and SLC transporters in drug-resistant ovarian cancer cell lines. Biomed Pharmacother 67: 240-245, 2013.

47. Seitz HK and Stickel F: Molecular mechanisms of alcoholmediated carcinogenesis. Nat Rev Cancer 7: 599-612, 2007.

48. Tsai ST, Wong TY, Ou CY, Fang SY, Chen KC, Hsiao JR, Huang CC, Lee WT, Lo HI, Huang JS, et al: The interplay between alcohol consumption, oral hygiene, ALDH2 and ADH1B in the risk of head and neck cancer. Int J Cancer 135: 2424-2436, 2014

49. Wu M, Chang SC, Kampman E, Yang J, Wang XS, Gu XP, Han RQ, Liu AM, Wallar G, Zhou JY, et al: Single nucleotide polymorphisms of ADH1B, ADH1C and ALDH2 genes and esophageal cancer: A population-based case-control study in China. Int J Cancer 132: 1868-1877, 2013.

50. Duell EJ, Sala N, Travier N, Muñoz X, Boutron-Ruault MC, Clavel-Chapelon F, Barricarte A, Arriola L, Navarro C, SánchezCantalejo E, et al: Genetic variation in alcohol dehydrogenase (ADH1A, ADH1B, ADH1C, ADH7) and aldehyde dehydrogenase (ALDH2), alcohol consumption and gastric cancer risk in the European Prospective Investigation into Cancer and Nutrition (EPIC) cohort. Carcinogenesis 33: 361-367, 2012.

51. Leclerc J, Courcot-Ngoubo Ngangue E, Cauffiez C, Allorge D, Pottier N, Lafitte JJ, Debaert M, Jaillard S, Broly F and Lo-Guidice JM: Xenobiotic metabolism and disposition in human lung: Transcript profiling in non-tumoral and tumoral tissues. Biochimie 93: 1012-1027, 2011.

52. Murray GI, Weaver RJ, Paterson PJ, Ewen SW, Melvin WT and Burke MD: Expression of xenobiotic metabolizing enzymes in breast cancer. J Pathol 169: 347-353, 1993.
53. Akman SA, Forrest G, Chu FF, Esworthy RS and Doroshow JH: Antioxidant and xenobiotic-metabolizing enzyme gene expression in doxorubicin-resistant MCF-7 breast cancer cells. Cancer Res 50: 1397-1402, 1990.

54. Tsuruoka S, Ishibashi K, Yamamoto H, Wakaumi M, Suzuki M, Schwartz GJ, Imai M and Fujimura A: Functional analysis of ABCA8, a new drug transporter. Biochem Biophys Res Commun 298: 41-45, 2002.

55. Januchowski R, Zawierucha P, Ruciński M, Andrzejewska M, Wojtowicz K, Nowicki M and Zabel M: Drug transporter expression profiling in chemoresistant variants of the A2780 ovarian cancer cell line. Biomed Pharmacother 68: 447-453, 2014.

56. Auersperg N: The stem-cell profile of ovarian surface epithelium is reproduced in the oviductal fimbriae, with increased stem-cell marker density in distal parts of the fimbriae. Int J Gynecol Pathol 32: 444-453, 2013.

57. Kim H, Lapointe J, Kaygusuz G, Ong DE, Li C, van de Rijn M, Brooks JD and Pollack JR: The retinoic acid synthesis gene ALDH1a2 is a candidate tumor suppressor in prostate cancer. Cancer Res 65: 8118-8124, 2005.

58. Ju ZH, Ying MG, Ai X, Shi TP, Wang BJ, Wang C, Zhang GX and Zhang X: Effects of 5-Aza-2'-deoxycitydine and trichostatin A on expression and apoptosis of ALDH1a2 gene in human bladder cancer cell lines. Zhonghua Wai Ke Za Zhi 48: 378-382, 2010 (In Chinese).

59. Moreb JS, Ucar D, Han S, Amory JK, Goldstein AS, Ostmark B and Chang LJ: The enzymatic activity of human aldehyde dehydrogenases $1 \mathrm{~A} 2$ and 2 (ALDH1A2 and ALDH2) is detected by Aldefluor, inhibited by diethylaminobenzaldehyde and has significant effects on cell proliferation and drug resistance. Chem Biol Interact 195: 52-60, 2012.

60. Kawasoe M, Yamamoto Y, Okawa K, Funato T, Takeda M, Hara T, Tsurumi H, Moriwaki H, Arioka Y, Takemura M, Matsunami H, Markey SP and Saito K: Acquired resistance of leukemic cells to AraC is associated with the upregulation of aldehyde dehydrogenase 1 family member A2. Exp Hematol 41: 597-603 e2, 2013.

61. Cortes-Dericks L, Froment L, Boesch R, Schmid RA and Karoubi G: Cisplatin-resistant cells in malignant pleural mesothelioma cell lines show ALDH(high)CD44(+) phenotype and sphere-forming capacity. BMC Cancer 14: 304, 2014.

62. Kim DH, Roh YG, Lee HH, Lee SY, Kim SI, Lee BJ and Leem SH: The E2F1 oncogene transcriptionally regulates NELL2 in cancer cells. DNA Cell Biol 32: 517-523, 2013.

63. Maeda K, Matsuhashi S, Tabuchi K, Watanabe T, Katagiri T, Oyasu M, Saito N and Kuroda S: Brain specific human genes, NELL1 and NELL2, are predominantly expressed in neuroblastoma and other embryonal neuroepithelial tumors. Neurol Med Chir (Tokyo) 41: 582-588, discussion 589, 2001.

64. Kuroda S, Oyasu M, Kawakami M, Kanayama N, Tanizawa K, Saito N, Abe T, Matsuhashi S and Ting K: Biochemical characterization and expression analysis of neural thrombospondin-1-like proteins NELL1 and NELL2. Biochem Biophys Res Commun 265: 79-86, 1999. 